\title{
Three-dimensional mitral valve structure in predicting moderate ischemic mitral regurgitation improvement after coronary artery bypass grafting
}

Xiaotian Sun, MD, PhD, ${ }^{a}$ Yuwen Jiang, MD, ${ }^{\mathrm{b}}$ Guoqian Huang, MD, PhD, ${ }^{\mathrm{b}}$ Jiechun Huang, MD, PhD,

Meng Shi, MD, ${ }^{\mathrm{a}}$ Liewen Pang, $\mathrm{MD},{ }^{\mathrm{a}}$ and Yiqing Wang, $\mathrm{MD}, \mathrm{PhD}^{\mathrm{a}}$

\section{ABSTRACT}

Objective: Focusing on 3-dimensional mitral valve structure, this study investigated predictors for moderate ischemic mitral regurgitation (IMR) improvement after off-pump coronary artery bypass grafting (OPCAB).

Methods: This study included 143 patients (age $67.6 \pm 7.6$ years, 32.9\% female) with previous myocardial infarction and moderate IMR undergoing OPCAB. Preoperative 3-dimensional echocardiographic data were analyzed, focusing on mitral annular geometry and leaflet tethering model. Patients were grouped according to IMR at 1-year postoperative follow-up into improved $(n=65)$, with no or mild IMR, and failure $(\mathrm{n}=70)$, with moderate or severe IMR, groups. Groups were compared to identify predictors of IMR improvement after OPCAB.

Results: Eight patients died within 1 year. At 1 postoperative year, improved group included 65 patients; failure group included 70. Improved group had less preoperative annular flattening (smaller nonplanar angle) and segmental leaflet tethering (smaller A3, P1, P2, and P3 tethering angles) than failure group. Nonplanar angle $(P<.001)$ and P3 tethering angle $(P<.001)$ were independent predictors of moderate IMR improvement after OPCAB. Receiver operator characteristic curves defined P3 tethering angle of $28.8^{\circ}$ (sensitivity of $78.6 \%$, specificity of $84.6 \%$ ) and nonplanar angle of $158.1^{\circ}$ (sensitivity, $64.3 \%$ and specificity of $86.2 \%$ ) as the cutoff values.

Conclusions: Preoperative moderate IMR can be improved by OPCAB in selected patients. Less annular flattening and P3 leaflet tethering may predict improvement of moderate IMR after OPCAB, suggesting that the annular nonplanar saddle shape and less leaflet tethering toward P3 segment are important for the prognosis of moderate IMR. (J Thorac Cardiovasc Surg 2019;157:1795-803)

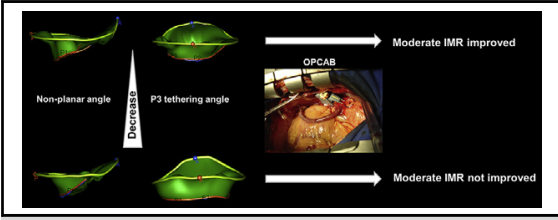

Patients with improved IMR after OPCAB show less annular flattening and $\mathrm{P} 3$ tethering.

Central Message

This study demonstrated that moderate IMR can be improved by OPCAB in selected cases, and less annular flattening and P3 leaflet tethering may predict the improvement of moderate IMR after OPCAB.

\section{Perspective}

This study suggested that the annular nonplanar saddle shape and less leaflet tethering toward the $\mathrm{P} 3$ segment are important for the prognosis of moderate IMR. OPCAB is recommended for such patients, particularly those with high surgical risks. Further studies are warranted to establish a risk model, which will allow optimization of surgical strategies for patients with different features of IMR.

See Commentaries on pages 1804 , 1806 , and 1808
Ischemic mitral regurgitation (IMR) is frequently associated with myocardial infarction; it involves left ventricular (LV) remodeling, papillary muscle displacement, leaflet tethering, and annular deformation, thus adversely affecting the rate of survival free of heart failure. ${ }^{1}$ Approximately $10 \%$ of patients with myocardial infarction have moderate IMR develop, and optimal surgical management of moderate IMR at the time of coronary artery bypass grafting $(\mathrm{CABG})$ remains controversial. Some experts advocate

\footnotetext{
From the Departments of ${ }^{\mathrm{a}}$ Cardiothoracic Surgery and ${ }^{\mathrm{b}}$ Echocardiography, Huashan Hospital of Fudan University, Shanghai, China.

Funded by the National Natural Science Foundation of China $(81601663,81772042)$, the Shanghai Municipal Health and Planning Commission Foundation (20164Y0177), and the Shanghai Natural Science Grant (16ZR1449400).

Received for publication March 24, 2018; revisions received Aug 8, 2018; accepted for publication Sept 4, 2018; available ahead of print Dec 6, 2018
}

restrictive mitral annuloplasty repair (MVR) at the time of $\mathrm{CABG}$ to reduce the degree of mitral regurgitation directly, thus preventing further adverse remodeling and presumably decreasing the risk of heart failure. ${ }^{2,3}$ A considerable number of patients, however, show persistent or recurrent IMR after annuloplasty, ${ }^{4}$ which adversely affects clinical outcomes. ${ }^{5}$ Furthermore, CABG plus MVR has not been shown to enhance long-term survival. ${ }^{4}$ Some specialists therefore support the use of revascularization alone to treat

\footnotetext{
Address for reprints: Yiqing Wang, MD, PhD, 12th Wulumuqi Rd, Shanghai, 200040 China (E-mail: wangyiqing@huashan.org.cn). 0022-5223/\$36.00

Copyright (C) 2018 by The American Association for Thoracic Surgery https://doi.org/10.1016/j.jtcvs.2018.09.018
} 


$$
\begin{aligned}
& \text { Abbreviations and Acronyms } \\
& \text { IMR = ischemic mitral regurgitation } \\
& \mathrm{LV} \quad=\text { left ventricular } \\
& \mathrm{CABG}=\text { coronary artery bypass grafting } \\
& \text { MVR = mitral valve repair } \\
& \text { LVEF }=\text { left ventricular ejection fraction } \\
& \mathrm{MV}=\text { mitral valve } \\
& 2 \mathrm{DE}=2 \text {-dimensional echocardiography } \\
& \text { RT-3DE }=\text { real-time 3-dimensional } \\
& \text { echocardiography } \\
& \text { 3D }=3 \text {-dimensional } \\
& \mathrm{OPCAB}=\text { off-pump coronary artery bypass }
\end{aligned}
$$

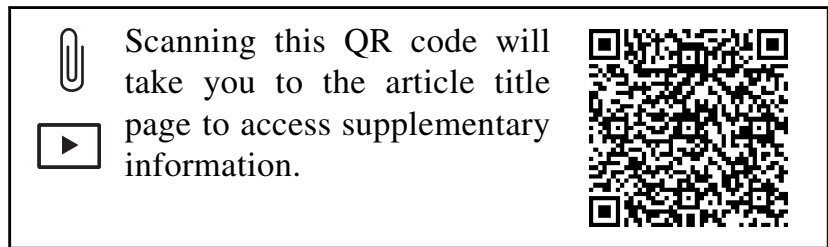

patients with moderate IMR, because the reversal of regional and global LV remodeling after CABG can reduce the degree of IMR. ${ }^{6}$ A recent randomized trial presented solid evidence that adding MVR to CABG had no clinical advantage at the 2-year follow-up. ${ }^{7}$ Considering the higher complication rate and mortality associated with CABG plus MVR compared with CABG alone for high-risk patients, ${ }^{2,7}$ the possibility that moderate IMR can be reduced after $\mathrm{CABG}$ alone raises concerns and hopes.

To date, few reliable predictors of IMR improvement after isolated CABG have been identified, including the presence of viable myocardium and the absence of $\mathrm{LV}$ dyssynchrony, ${ }^{6,8}$ reserved LV ejection fraction (LVEF),,${ }^{9,10}$ as well as LV posteroinferior regional remodeling. ${ }^{10}$ In patients with such features, moderate IMR would be more easily improved by CABG alone. The mitral valve (MV) structure, however, including annular geometry and leaflet modeling, has not been fully elucidated as an important and direct cause of IMR. The structure of the MV is conventionally assessed with 2-dimensional echocardiography (2DE), which is highly dependent on viewing plane selection and recognition of anatomic landmarks. Studies reporting preoperative $\mathrm{MV}$ data obtained with $2 \mathrm{DE}$ therefore show inconsistent and conflicting results, with no value for the analysis of MV structure. ${ }^{11}$

Real-time three-dimensional echocardiography (RT-3DE) has recently become a useful clinical tool that can accurately quantify and analyze the complex 3-dimensional (3D) geometry of the MV. With advanced image modeling, RT-3DE has been shown to assess MV anatomy, geometry, and dynamics accurately, including the annular and leaflet tethering modeling. ${ }^{12}$ This study investigated the predictors of moderate IMR improvement after off-pump CABG $(\mathrm{OPCAB})$ in MV annular and leaflet tethering modeling performed with RT-3DE.

\section{METHODS \\ Study Population}

This study was approved and monitored by the institutional review board of the Huashan Hospital, Shanghai, China. Written, informed consent was obtained from all included patients. Between May 2008 and Jan 2016, a total of 1231 patients with left main or proximal 3-vessel disease, including 1089 patients undergoing $\mathrm{OPCAB}$, underwent isolated $\mathrm{CABG}$ in the study institution. All patients with moderate IMR undergoing OPCAB were assessed for eligibility according to the following criteria: (1) previous myocardial infarction at least 16 days before, (2) a corresponding regional wall motion abnormality detected by echocardiography, (3) a structurally normal MV, (4) sinus rhythm, and (5) high quality of available echocardiographic images, allowing 3D valve analysis. Patients with other valvular or congenital heart diseases, structural abnormalities of the mitral apparatus, atrial fibrillation, and inadequate image qualities inappropriate for performing quantitative reconstruction of the valve were excluded. After the exclusion of 26 patients, 143 patients were enrolled in the study; they underwent OPCAB as the only surgical procedure, after which they received the same medical therapies, such as diuretics (flow chart shown in Figure E1).

\section{Study Protocol}

In our institution, patients with moderate or less IMR underwent OPCAB unless they had aortic valvular lesions, whereas patients with severe IMR underwent both CABG and concomitant MVR. Preoperative clinical characteristics and echocardiographic results were collected from patients with moderate IMR. The patients were regularly followed up with echocardiography, and according to the IMR changes observed at 1-year follow-up, they were grouped into either the improved group (if they had absent or mild IMR $[n=65]$ ), or the failure group (if they had moderate or severe IMR $[n=70])$. Preoperative and postoperative data were compared between the groups, and predictors of IMR improvement were investigated. To avoid selection bias, clinical data, 2DE, and RT-3DE were separately studied by 3 researchers, and no measurements were repeated.

\section{Preoperative Echocardiography}

Two-dimensional echocardiography. Preoperative echocardiography was performed 1 week before surgery. All patients underwent standard transthoracic echocardiography with the Philips IE 33 system (S5-1 probe, 2.5-5.5 MHz; Koninklijke Philips N.V., Amsterdam, The Netherlands). Images were acquired through a transthoracic apical 4-chamber view, and mitral regurgitation severity was evaluated by measuring the ratio of the color flow regurgitant jet area to left atrial area by color mapping the apical 4-chamber view during cardiac systole as mild $(<20 \%)$, moderate $(20 \%-40 \%)$, or severe $(>40 \%) .{ }^{13} \mathrm{LV}$ end-diastolic and systolic diameters were obtained from the M-mode tracings, and LVEF was assessed with the biapical Simpson disk method. ${ }^{14}$ The mean wall motion score index was calculated according to a 17-segment model.

Real-time 3D geometric analysis for annular and leaflet modeling. Each full-volume preoperative 3D echocardiographic data set was exported to an Echo-View 5.4 (TomTec 4D MV-Assessment Imaging Systems, Munich, Germany) software workstation. All analyses were performed at midsystole from a single cardiac cycle. The techniques used for annular segmentation and modeling have been described previously. ${ }^{12}$ Briefly, the Cartesian $(x, y, z)$ coordinates of each data point were exported from the TomTec Echo-View to the MATLAB software (The MathWorks, Natick, Mass) to reconstruct the valve quantitatively. 


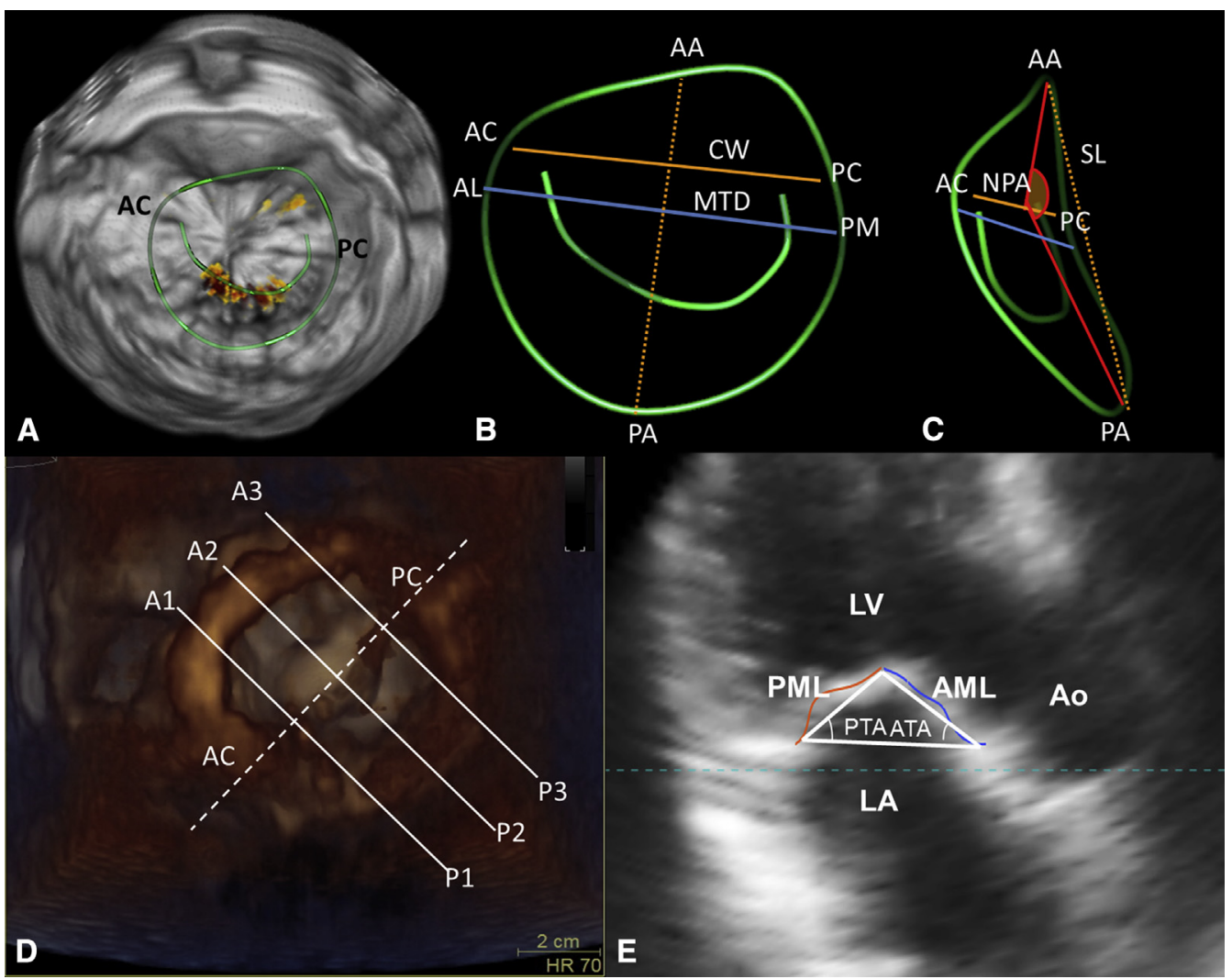

FIGURE 1. Real-time 3-dimensional analysis method for annular and leaflet modeling. A, Representative 3-dimensional echocardiographic volume containing the mitral valve with traced annular (green) and regurgitation (yellow). B and C, Transvalvular (B) and oblique (C) annular views of a single real-time 3-dimensional-derived mitral annular model with annular landmarks. D, Representative transverse cross-sections along the intercommissural axis in $\mathrm{A} 1$ to $\mathrm{P} 1, \mathrm{~A} 2$ to $\mathrm{P} 2$, and $\mathrm{A} 3$ to $\mathrm{P} 3$ segments. E, One of the representative 2-dimensional cross-sections in panel D; the surface of the mitral leaflets is marked (red and blue curves), with the anterior tethering angle (ATA) and the posterior tethering angle (PTA) marked. Yellow line represents commissural width; yellow dashed line represents septolateral diameter; blue line represents mitral transverse diameter. Red angle represents nonplanar angle (NPA). $A C$, Anterior commissure; $P C$, posterior commissure; $A A$, anterior mitral annulus; $C W$, commissural width; $A L$, anterolateral annulus; $M T D$, mitral transverse diameter; $P M$, posteromedial annulus; $S L$, septolateral diameter; $P A$, posterior mitral annulus; $L V$, left ventricle; $P M L$, posterior mitral leaflet; $A M L$, anterior mitral leaflet; $A o$, aorta; $L A$, left atrium.

Geometric variables were automatically calculated as follows: septolateral diameter was defined as the distance separating the septum and lateral annulus; commissural width was defined as the distance between the commissures; and mitral transverse diameter was the widest diameter of the MV and was calculated as the distance between the anterolateral annulus and posteromedial annulus. The mitral annular area was defined as the area enclosed by the 2-dimensional projection of a given annular data set onto its corresponding least squares (MV orifice) plane. The mitral annular circumference was defined as the total 3D length of the annulus. The nonplanar angle was defined as the angle between the mitral anterior annulus and the posterior annulus planes. The MV tethering angles in 6 standard anatomic leaflet segments (A1, A2, A3; P1, P2, and P3) were calculated with previously described methods (Figure 1).12,15

\section{Surgical Procedures}

All surgical procedures were performed through a midline sternotomy. In patients younger than 75 years, the left internal thoracic artery was harvested and grafted to the left anterior descending coronary artery. In patients younger than 60 years, saphenous veins and radial arteries were harvested and grafted to the remaining coronary arteries with sequential aortocoronary bypass grafting. The Medtronic Starfish cardiac positioner and Octopus stabilizer (Medtronic Inc, Minneapolis, Minn) were used for all patients. Anastomoses of the left internal thoracic artery to the left anterior descending coronary artery were performed with 7-0 Prolene sutures (Ethicon, Inc, Somerville, NJ), whereas other anastomoses were performed with 6-0 Prolene sutures. Complete revascularization was accomplished for all patients.

\section{Follow-up}

All patients were followed-up by a single researcher who was blinded to the echocardiographic assessment. Early postoperative echocardiography was performed before discharge, and echocardiography of each patient were also performed and analyzed within 2 weeks of exactly 1 postoperative year.

\section{Statistical Analysis}

All statistical analyses were performed with the SPSS Statistics Base 17.0 (Released 2008, SPSS Statistics for Windows, version17.0; IBM, Armonk, NY). Continuous data were checked for the normal distribution and expressed as mean $\pm \mathrm{SD}$, and group comparisons were analyzed with the paired or unpaired Student $t$ test as appropriate. Categorical variables were compared with the $\chi^{2}$ test. Multivariable logistic regression analysis was used to determine the independent predictors of IMR 
improvement. Univariate preoperative clinical and echocardiographic variables with a $P$ value of less than .05 were included in the multivariate analysis by forward stepwise selection, and the Hosmer-Lemeshow test was used to check the goodness of fit. Receiver operating characteristic curves were created from the obtained predictor, and univariate associations were analyzed to obtain the "optimal" cutoff value on the receiver operating characteristic curve closest to the point $(0,1)$.

\section{RESULTS}

The average number of grafts per patient was 3.91. No in-hospital deaths were recorded. Eight patents died before the 1-year follow-up echocardiographic assessment ( 2 of low output syndrome, 5 of multiorgan failure, and 1 of cerebrovascular accident). In the remaining 135 patients, the 1-year follow-up echocardiography detected 59 mild and 6 nonobvious cases of mitral regurgitation within the improved group, whereas the Failure Group included 54 moderate and 16 severe cases of mitral regurgitation. No significant differences regarding the clinical baseline characteristics, except for LVEF, were found between the study groups (Table 1). At the 1-year follow-up, the mean wall motion score index was similar between the groups (improved group vs failure group, $1.71 \pm 0.45$ vs $1.68 \pm 0.42 ; P=.604)$. In addition, at 1-year after surgery, both improved and failure groups presented reduced (or tendency to be reduced) LVend-diastolic diameter (baseline vs 1 postoperative year, $52.9 \pm 8.1$ vs $48.5 \pm 10.8 ; P=.010$ in the improved group; and $54.6 \pm 8.9$ vs $51.1 \pm 9.9$; $P=.031$ in the failure group) and LV end-systolic diameter (baseline vs 1 postoperative year, $39.9 \pm 7.8$ vs $37.0 \pm 5.9$; $P=.019$ in the improved group; and $41.9 \pm 12.5$ vs $38.6 \pm 9.9 ; P=.088$ in the failure group), with significantly improved postoperative LVEF (baseline vs 1 postoperative year, $42.9 \pm 12.3$ vs. $49.2 \pm 4.5 ; P<.001$ in the improved group; and $37.4 \pm 15.1$ vs $41.4 \pm 6.8 ; P=.046$ in the failure group).

\section{RT-3DE Analysis of MV Structure}

Baseline and follow-up 3D echocardiographic parameters are shown in Table 2. At baseline, the diameters, sphericity index, circumferences, and areas of the mitral annulus were similar for the 2 groups. Patients in the improved group, however, showed a significantly lower nonplanar angle than did the failure group. With respect to the MV leaflet tethering, although no group difference was observed for the baseline preoperative tethering angle of $\mathrm{A} 1$ or $\mathrm{A} 2$, the tethering angles of $\mathrm{A} 3, \mathrm{P} 1, \mathrm{P} 2$, and $\mathrm{P} 3$ in the improved group were lower than those in the failure group, with a tendency to further decrease at follow-up. Accordingly, preoperative MV tethering volumes tended to increase in the failure group relative to those in the improved group. Virtual renderings of representative mitral valves derived with $3 \mathrm{D}$ echocardiography demonstrated an
TABLE 1. Preoperative and intraoperative patient characteristics

\begin{tabular}{|c|c|c|c|}
\hline Characteristics & $\begin{array}{l}\text { Improved } \\
\text { group } \\
(\mathbf{n}=65)\end{array}$ & $\begin{array}{l}\text { Failure } \\
\text { group } \\
(n=70)\end{array}$ & $\begin{array}{c}P \\
\text { value }\end{array}$ \\
\hline Age (y) & $68.3 \pm 7.7$ & $66.7 \pm 7.9$ & .241 \\
\hline Female (No.) & $21(32.3 \%)$ & $25(35.7 \%)$ & .719 \\
\hline $\begin{array}{l}\text { NYHA class (No.) } \\
\text { Class } 2 \\
\text { Class } 3 \\
\text { Class } 4\end{array}$ & $\begin{array}{c}8(12.3 \%) \\
55(84.6 \%) \\
2(3.1 \%)\end{array}$ & $\begin{array}{c}10(14.3 \%) \\
56(80.0 \%) \\
4(5.7 \%)\end{array}$ & .700 \\
\hline Smoking (No.) & $15(23.1 \%)$ & $16(22.9 \%)$ & $>.999$ \\
\hline Diabetes (No.) & $23(35.4 \%)$ & $21(30.0 \%)$ & .583 \\
\hline Chronic renal failure (No.) & $7(10.7 \%)$ & $6(8.6 \%)$ & .774 \\
\hline Hypertension (No.) & $28(43.1 \%)$ & $27(38.0 \%)$ & .604 \\
\hline COPD (No.) & $7(10.7 \%)$ & $6(8.6 \%)$ & .774 \\
\hline Heart rate (beats/min) & $70.8 \pm 10.8$ & $69.1 \pm 10.0$ & .325 \\
\hline $\begin{array}{l}\text { Left bundle-branch } \\
\text { block (No.) }\end{array}$ & $16(24.6 \%)$ & $19(27.1 \%)$ & .845 \\
\hline CHF (No.) & $5(7.7 \%)$ & $7(10.0 \%)$ & .766 \\
\hline $\begin{array}{l}\text { Previous MI (No.) } \\
\text { Inferior or posterior } \\
\text { Anterior } \\
\text { Both }\end{array}$ & $\begin{array}{l}26(40.0 \%) \\
22(33.8 \%) \\
17(26.2 \%)\end{array}$ & $\begin{array}{l}19(27.1 \%) \\
27(38.6 \%) \\
24(34.3 \%)\end{array}$ & $\begin{array}{l}.144 \\
.595 \\
.351\end{array}$ \\
\hline $\begin{array}{l}\text { Left ventricular parameters } \\
\text { End-diastolic diameter } \\
\quad(\mathrm{cm})\end{array}$ & $52.9 \pm 8.1$ & $54.6 \pm 8.9$ & .252 \\
\hline $\begin{array}{l}\text { End-systolic diameter } \\
\quad(\mathrm{cm})\end{array}$ & $39.9 \pm 7.8$ & $41.9 \pm 12.5$ & .262 \\
\hline $\begin{array}{l}\text { Mean wall-motion score } \\
\text { index }\end{array}$ & $1.90 \pm 0.51$ & $1.85 \pm 0.49$ & .601 \\
\hline IMR jet area/LA area (\%) & $29.2 \% \pm 6.3 \%$ & $31.1 \% \pm 5.3 \%$ & .750 \\
\hline LITA used (No.) & $58(89.2 \%)$ & $64(91.4 \%)$ & .774 \\
\hline IABP application (No.) & $6(9.2 \%)$ & $5(7.1 \%)$ & .758 \\
\hline $\begin{array}{l}\text { Grafted vessels (No.) } \\
3 \text { vessels } \\
4 \text { vessels } \\
5 \text { vessels }\end{array}$ & $\begin{array}{r}14(21.5 \%) \\
44(67.7 \%) \\
7(10.8 \%)\end{array}$ & $\begin{array}{l}18(25.7 \%) \\
40(57.1 \%) \\
12(17.1 \%)\end{array}$ & .402 \\
\hline \multicolumn{4}{|l|}{ Grafted coronary vessels (No.) } \\
\hline $\begin{array}{l}\text { LAD } \\
\text { LCX } \\
\text { RCA }\end{array}$ & $\begin{array}{l}58(89.2 \%) \\
35(53.8 \%) \\
40(61.5 \%)\end{array}$ & $\begin{array}{l}64(91.4 \%) \\
39(55.7 \%) \\
33(47.1 \%)\end{array}$ & $\begin{array}{l}.744 \\
.864 \\
.120\end{array}$ \\
\hline Operation time (min) & $219.4 \pm 32.4$ & $223.8 \pm 33.8$ & .436 \\
\hline ICU stay (h) & $40.5 \pm 5.9$ & $40.8 \pm 4.9$ & .200 \\
\hline In-hospital stay (d) & $10.2 \pm 2.0$ & $9.7 \pm 2.2$ & .108 \\
\hline
\end{tabular}

All values are given as mean $\pm \mathrm{SD}$ or $\mathrm{n}(\%)$. NYHA, New York Heart Association; $C O P D$, chronic obstructive pulmonary disease; $C H F$, congestive heart failure; $M I$, myocardial infarction; $I M R$, ischemic mitral regurgitation; $L A$, left atrial; LITA, left internal thoracic artery; IABP, intra-aortic balloon pump; $L A D$, left anterior descending coronary artery; $L C X$, left circumflex artery; $R C A$, right coronary artery; $I C U$, intensive care unit. 
obvious annular flattening and augmented leaflet tethering toward the posterior commissure of the MV in the failure group, which would lead to a persisting IMR after CABG (Figure 2).

\section{Predictors of IMR Improvement}

Preoperative factors with differences between groups were further analyzed with binary logistic regression. The P3 tethering angle (odds ratio, 0.697; $P<.001 ; 95 \%$ confidence interval, 0.602-0.807) and nonplanar angle (odds ratio, $0.769 ; P<.001 ; 95 \%$ confidence interval, 0.679-0.870) emerged as independent predictors of moderate IMR improvement after OPCAB (Table 3). . Receiver operating characteristic curves defined the P3 tethering angle of $28.8^{\circ}$ (sensitivity, $78.6 \%$; specificity, $84.6 \%$ ) and the nonplanar angle of $158.1^{\circ}$ (sensitivity, $64.3 \%$; specificity, $86.2 \%$ ) as the cutoff values (Figure 3).

\section{DISCUSSION}

This study identified 2 independent predictors of moderate IMR improvement after OPCAB: the P3 tethering angle and the annular nonplanar angle. Our results suggest that complete revascularization can relieve moderate IMR in selected patients with a lower flattened MV annulus and segmental MV tethering toward the posterior commissure. These annular and leaflet modeling features are helpful to identify suitable patients with moderate IMR who can benefit from isolated CABG in terms of IMR changes and related prognosis.

The Cardiothoracic Surgical Trials Network conducted a very important multicenter, randomized trial comparing CABG alone with CABG plus MVR (combined procedure) in patients with moderate IMR. At 1 and 2 postoperative years, ${ }^{7,16}$ no significant differences regarding LV reverse remodeling, survival, or major adverse cardiac and cerebrovascular events were observed between the approaches. Furthermore, the CABG plus MVR procedure was associated with longer crossclamp or bypass times, longer duration of postoperative hospital stay, increased incidence of postoperative supraventricular arrhythmias, and higher rates of serious neurologic events. According to these results, isolated CABG is a promising and reliable approach for surgical management of moderate IMR. OPCAB has been shown to have even more advantages by avoiding the potentially detrimental effects of cardiopulmonary bypass and eliminating intraoperative global myocardial ischemia, particularly in high-risk patients. ${ }^{17}$ Preoperative identification of patients likely to benefit from OPCAB thus encompasses significant advantages.

In IMR, the regional 3D pathologic anatomy of MV is highly complex and varies significantly among patients. Although regular annular variables can be obtained from conventional $2 \mathrm{DE}$, this method is unreliable for measuring
TABLE 2. Three-dimensional echocardiographic annular and leaflet tethering variables at baseline and 1-year postoperative follow-up

\begin{tabular}{|c|c|c|c|}
\hline & $\begin{array}{c}\text { Improved } \\
\text { group } \\
(\mathbf{n}=65)\end{array}$ & $\begin{array}{c}\text { Failure } \\
\text { group } \\
(\mathbf{n}=\mathbf{7 0})\end{array}$ & $\begin{array}{c}P \\
\text { value }\end{array}$ \\
\hline \multicolumn{4}{|c|}{ Septolateral diameter (mm) } \\
\hline Baseline & $30.2 \pm 3.2$ & $31.0 \pm 3.7$ & .183 \\
\hline Follow-up & $29.9 \pm 3.4$ & $31.0 \pm 4.0$ & .101 \\
\hline \multicolumn{4}{|c|}{ Commissural width (mm) } \\
\hline Baseline & $31.3 \pm 3.7$ & $32.2 \pm 3.7$ & .178 \\
\hline Follow-up & $30.9 \pm 4.2$ & $32.3 \pm 4.5$ & .054 \\
\hline \multicolumn{4}{|c|}{ Mitral transverse diameter (mm) } \\
\hline Baseline & $36.4 \pm 4.1$ & $36.5 \pm 4.6$ & .883 \\
\hline Follow-up & $35.9 \pm 4.3$ & $36.7 \pm 5.0$ & .375 \\
\hline \multicolumn{4}{|c|}{ Annular circumference (mm) } \\
\hline Baseline & $112.4 \pm 9.1$ & $112.7 \pm 10.3$ & .840 \\
\hline Follow-up & $110.9 \pm 8.9$ & $113.4 \pm 10.9$ & .137 \\
\hline \multicolumn{4}{|c|}{ Mitral annular area $\left(\mathrm{mm}^{2}\right)$} \\
\hline Baseline & $863.0 \pm 135.8$ & $877.1 \pm 160.3$ & .582 \\
\hline Follow-up & $838.4 \pm 130.6$ & $880.0 \pm 160.6$ & .100 \\
\hline \multicolumn{4}{|c|}{ Annular sphericity index } \\
\hline Baseline & $0.96 \pm 0.07$ & $0.94 \pm 0.08$ & .132 \\
\hline Follow-up & $0.97 \pm 0.06$ & $0.95 \pm 0.07$ & .236 \\
\hline \multicolumn{4}{|c|}{ Nonplanar angle $\left({ }^{\circ}\right)$} \\
\hline Baseline & $150.6^{\circ} \pm 7.0^{\circ}$ & $160.4^{\circ} \pm 7.6^{\circ}$ & $<.001$ \\
\hline Follow-up & $148.6^{\circ} \pm 7.3^{\circ}$ & $162.7^{\circ} \pm 7.2^{\circ}$ & $<.001$ \\
\hline \multicolumn{4}{|c|}{ Mitral valve tethering volume $\left(\mathrm{mm}^{3}\right)$} \\
\hline Baseline & $2270.6^{\circ} \pm 1283.1^{\circ}$ & $2607.3 \pm 1716.0^{\circ}$ & .197 \\
\hline Follow-up & $2158.6^{\circ} \pm 1024.0^{\circ}$ & $3071.2^{\circ} \pm 1793.4^{\circ} *$ & $<.001$ \\
\hline \multicolumn{4}{|c|}{ A1 tethering angle $\left({ }^{\circ}\right)$} \\
\hline Baseline & $21.0^{\circ} \pm 6.8^{\circ}$ & $22.4^{\circ} \pm 8.5^{\circ}$ & .279 \\
\hline Follow-up & $20.6^{\circ} \pm 6.3^{\circ}$ & $22.9^{\circ} \pm 8.3^{\circ}$ & .068 \\
\hline \multicolumn{4}{|c|}{ A2 tethering angle $\left({ }^{\circ}\right)$} \\
\hline Baseline & $25.8^{\circ} \pm 10.0^{\circ}$ & $29.0^{\circ} \pm 10.5^{\circ}$ & .071 \\
\hline Follow-up & $25.2^{\circ} \pm 9.7^{\circ}$ & $29.9^{\circ} \pm 9.8^{\circ}$ & .006 \\
\hline \multicolumn{4}{|c|}{ A3 tethering angle $\left({ }^{\circ}\right)$} \\
\hline Baseline & $20.2^{\circ} \pm 6.8^{\circ}$ & $22.8^{\circ} \pm 8.4^{\circ}$ & .048 \\
\hline Follow-up & $19.7^{\circ} \pm 6.2^{\circ}$ & $23.4^{\circ} \pm 8.1^{\circ}$ & .004 \\
\hline \multicolumn{4}{|c|}{ P1 tethering angle $\left({ }^{\circ}\right)$} \\
\hline Baseline & $24.5^{\circ} \pm 9.0^{\circ}$ & $27.2^{\circ} \pm 6.4^{\circ}$ & .047 \\
\hline Follow-up & $24.0^{\circ} \pm 8.7^{\circ}$ & $27.6^{\circ} \pm 6.7^{\circ}$ & .010 \\
\hline \multicolumn{4}{|c|}{$\mathrm{P} 2$ tethering angle $\left({ }^{\circ}\right)$} \\
\hline Baseline & $29.6^{\circ} \pm 9.9^{\circ}$ & $33.2^{\circ} \pm 8.2^{\circ}$ & .024 \\
\hline Follow-up & $29.2^{\circ} \pm 9.2^{\circ}$ & $33.5^{\circ} \pm 8.2^{\circ}$ & .005 \\
\hline \multicolumn{4}{|c|}{ P3 tethering angle $\left({ }^{\circ}\right)$} \\
\hline Baseline & $21.5^{\circ} \pm 6.8^{\circ}$ & $33.0^{\circ} \pm 5.9^{\circ}$ & $<.001$ \\
\hline Follow-up & $21.0^{\circ} \pm 6.5^{\circ}$ & $33.4^{\circ} \pm 6.3^{\circ}$ & $<.001$ \\
\hline
\end{tabular}

Data are mean $\pm \mathrm{SD} . * P<.05$ (preoperation versus follow-up)

MV geometry because of possible incorrect viewing plane selection and regional valvular asymmetry. ${ }^{11}$ Full RT-3DE emerges as an advanced method for MV imaging and modeling analysis. Unlike $2 \mathrm{DE}$, the $3 \mathrm{D}$ method is not affected by the viewing plane selection, regional asymmetry, or localized annular distortions. It therefore 
serves as a useful tool for quantifying the complex geometry of the entire MV, with the possibility of accurately measuring specific variables, such as annular nonplanar angle and segmental tethering angles, which are unique to 3D imaging approaches.

Annular deformation and leaflet tethering occur to some degree in patients with IMR; however, their predictive effects regarding the improvement of IMR after myocardial revascularization have not been reported. Despite a similar degree of annular dilatation between the groups, patients in the improved group showed a significantly lower nonplanar angle than those in the failure group. Furthermore, a preoperative nonplanar angle less than $158.1^{\circ}$ emerged as an independent predictor of IMR improvement after OPCAB. This suggests that when compared with annular dilatation, annular distortion plays a crucial role in predicting the IMR prognosis after effective revascularization. There exists strong evidence that the typical saddle shape of the normal mitral annulus is important for valve function, because its nonplanarity can reduce peak leaflet stress by optimizing the leaflet curvature, thus preventing further valve insufficiency. In contrast, MV flattening may increase the stress of the annulus and leaflet, thus inducing IMR and reducing longevity of the repaired valve. ${ }^{18}$ Effective revascularization can reverse regional LV remodeling and leaflet tethering to some extent, which may subsequently relieve IMR. The flattened annulus may be more highly reversed by revascularization alone, however, thus requiring an MV ring to restore the normal annular saddle shape. $^{19}$

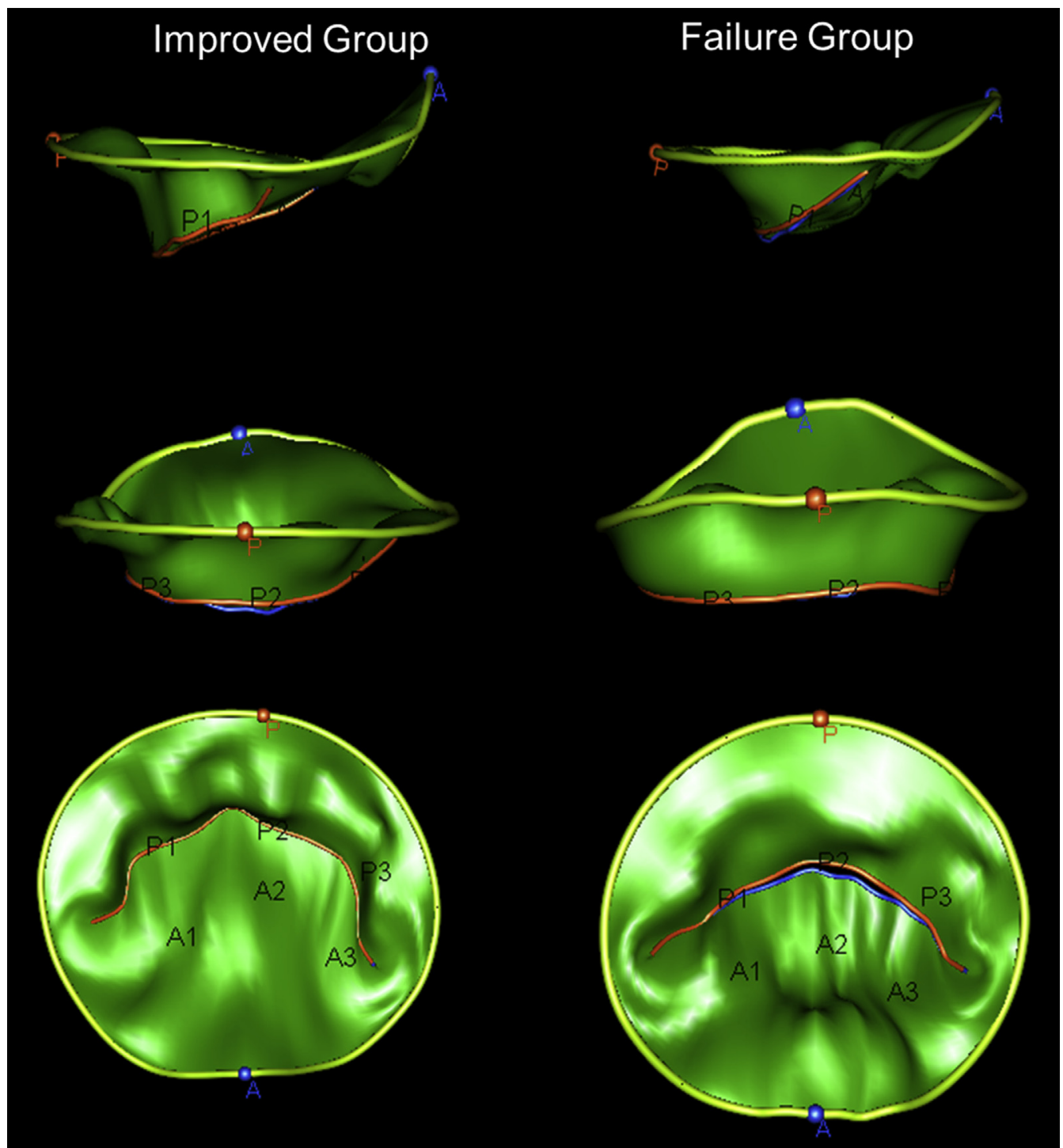

FIGURE 2. Three-dimensional echocardiographic virtual models of a representative preoperative mitral valves in improved and failure groups. Top row: Oblique commissure-to-commissure view. Middle row: Oblique septolateral view. Bottom row: Left ventricular view. 
TABLE 3. Predictors of ischemic mitral regurgitation improvement by binary logistic regression analysis

\begin{tabular}{lrcr}
\hline \multicolumn{1}{c}{ Determinants } & Coefficient \pm SE & OR $(\mathbf{9 5} \%$ CI $)$ & $P$ value \\
\hline Nonplanar angle & $-0.263 \pm 0.063$ & $0.769(0.679-0.870)$ & $<.001$ \\
P3 tethering angle & $-0.361 \pm 0.075$ & $0.697(0.602-0.807)$ & $<.001$ \\
\hline A3 tethering angle & $-0.047 \pm 0.038$ & $0.954(0.886-1.027)$ & .211 \\
\hline P1 tethering angle & $-0.012 \pm 0.039$ & $0.988(0.915-1.068)$ & .767 \\
P2 tethering angle & $-0.020 \pm 0.035$ & $0.980(0.915-1.049)$ & .563 \\
Ejection fraction & $0.015 \pm 0.024$ & $1.015(0.967-1.065)$ & .542 \\
\hline
\end{tabular}

$O R$, Odds ratio; $C I$, confidence interval.

Another important finding is that patients in the improved group had a significantly lower preoperative P3 tethering angle. A P3 tethering angle of less than $28.8^{\circ}$ was identified as another predictor of IMR improvement. Leaflet tethering has long been determined as a cause of recurrent IMR, and less tethering should theoretically be more likely to be improved after effective revascularization; however, none of the leaflet tethering baseline measures had been found to be predictive of changes of IMR after revascularization. ${ }^{20}$ With RT-3DE, our study identified the segmental valve tethering, particularly toward the posterior commissure, which could not be accurately assessed with 2DE. It has been also reported that the P3 tethering angle is closely related to the IMR prognosis after CABG plus MVR. ${ }^{15,21}$ These new findings further highlight the advantages of RT-3DE in confirming the complex 3D pathologic anatomy of IMR within different MV segments.

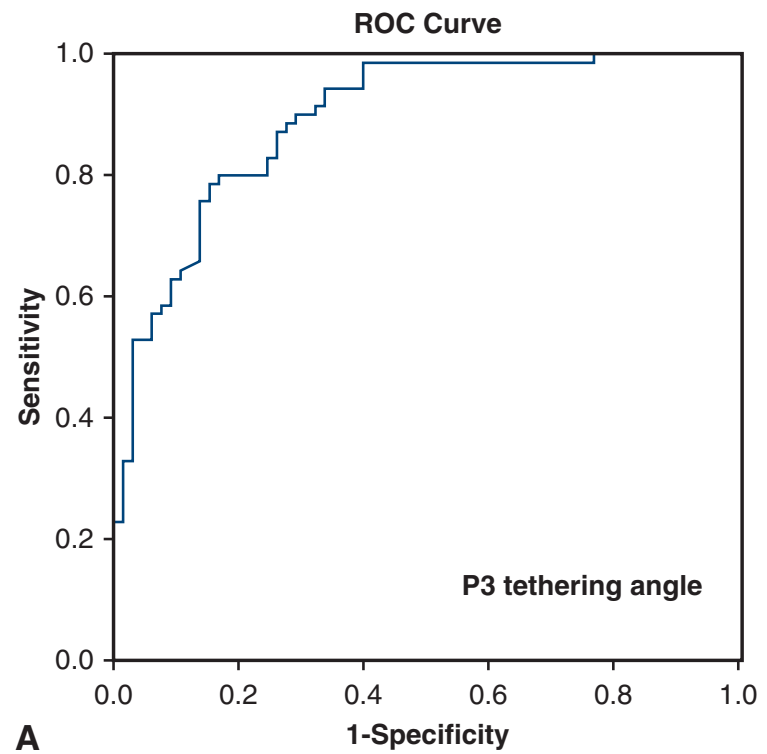

Patients with improved IMR after CABG have higher long-term survival, improved New York Heart Association functional class, and lesser complications. ${ }^{6,10}$ Conversely, residual IMR after surgery negatively impacts survival. ${ }^{22}$ These facts highlight the importance of identifying patients who potentially will benefit from isolated CABG. Our study demonstrates that a lower annular flattening and P3 tethering strongly predict postoperative IMR improvement, which may have important clinical implications in optimizing the surgical strategy. Furthermore, our quantitative geometric insights into annular modeling may also have direct implications for the design of annuloplasty devices that may restore the 3D shape of the normal annulus.

This study has several limitations. First, the severity of IMR was evaluated by transthoracic echocardiography but not by the transesophageal method, and by a semiquantitative assessment of regurgitant color flow jet area ratio but not by a more accurate assessment of the effective regurgitant orifice area. Semiquantitative assessment performed by an experienced echocardiographer through transthoracic echocardiography is still the commonest method used to identify significant IMR, however, and the combination of methods further ensures accuracy. Second, although the wall motion scores were completely evaluated preoperatively and postoperatively, a direct assessment of myocardial viability should be performed in further studies to help develop treatment strategies. Third, the main end point was the echocardiographic IMR change, rather than a clinical outcome such as survival. There is strong

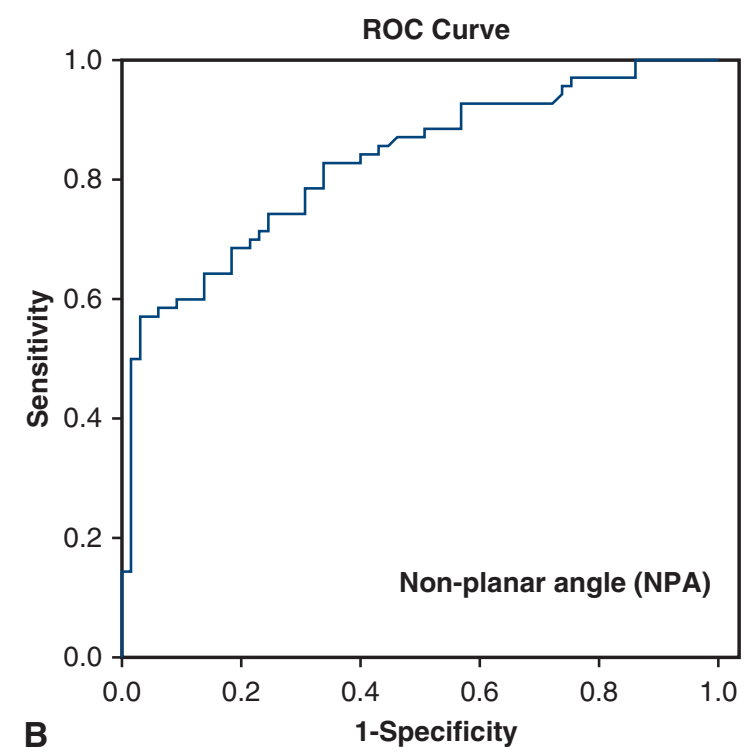

FIGURE 3. Receiver operating characteristic $(R O C)$ curves for predictors. A, P3 tethering angle. Area under the curve is 0.892 ( $95 \%$ confidence interval, $0.839-0.945$ ). Cutoff value is $28.8^{\circ}$, with sensitivity of $78.6 \%$ and specificity of $84.6 \%$. B, Nonplanar angle (NPA). Area under the curve is 0.829 ( $95 \%$ confidence interval, $0.760-0.897$ ). Cutoff value is $158.1^{\circ}$, with sensitivity of $64.3 \%$ and specificity of $86.2 \%$. 




VIDEO 1. The introduction of the major findings of this work and its potential clinical applications. $C A B G$, Coronary artery bypass grafting; IMR, ischemic mitral regurgitation; $O P C A B$, off-pump coronary artery bypass grafting; $A A$, anterior mitral annulus; $A C$, anterior commissure; $C W$, commissural width; $S L$, septolateral diameter; $P C$, posterior commissure; $N P A$, nonplanar angle; $A L$, anterolateral annulus; $M T D$, mitral transverse diameter; $P M$, posteromedial annulus; $P A$, posterior mitral annulus; $L V$, left ventricle; $P M L$, posterior mitral leaflet; $A M L$, anterior mitral leaflet; $A o$, aorta; $L A$, left atrium; $R O C$, receiver operating characteristic. Video available at: https://www.jtcvs.org/article/S0022-5223(18)32519-4/fulltext.

evidence, however, correlating residual IMR with reduced survival. Furthermore, as with other observational studies, ours cannot totally exclude observational bias, and there may also be residual confounding on the basis of mitral valve geometry and IMR improvement. Finally, this is a single-center study with a relatively small sample, and revascularization is only performed by off-pump approach. Further multicenter studies with various techniques are warranted to validate our conclusions.

\section{CONCLUSIONS}

In summary, isolated CABG could relieve IMR in selected patients with moderate IMR. A lower preoperative annular flattening (nonplanar angle $<158.1^{\circ}$ ) and segmental leaflet tethering $\left(\mathrm{P} 3\right.$ tethering angle $<28.8^{\circ}$ ) can predict the improvement of moderate IMR. OPCAB may therefore benefit these patients, particularly those with high surgical risks. Concomitant MVR might be suggested, however, for patients with obvious annular flattening and P3 leaflet tethering. Further studies with a larger sample size and longer follow-up are warranted in the future to establish a risk model, which will allow the optimization of surgical strategies for patients with different features of IMR (Appendix E1 and Video 1).

\section{Conflict of Interest Statement}

Authors have nothing to disclose with regard to commercial support.

\section{References}

1. Grigioni F, Detaint D, Avierinos JF, Scott C, Tajik J, Enriquez-Sarano M. Contribution of ischemic mitral regurgitation to congestive heart failure after myocardial infarction. J Am Coll Cardiol. 2005;45:260-7.

2. Chan KM, Punjabi PP, Flather M, Wage R, Symmonds K, Roussin I, et al. RIME Investigators. Coronary artery bypass surgery with or without mitral valve annuloplasty in moderate functional ischemic mitral regurgitation: final results of the randomized ischemic mitral evaluation (RIME) trial. Circulation. 2012; 126:2502-10.

3. ten Brinke EA, Klautz RJ, Tulner SA, Verwey HF, Bax JJ, Delgado V, et al. Clinical and functional effects of restrictive mitral annuloplasty at midterm follow-up in heart failure patients. Ann Thorac Surg. 2010;90:1913-20.

4. Bouchard D, Jensen H, Carrier M, Demers P, Pellerin M, Perrault LP, et al. Effect of systematic downsizing rigid ring annuloplasty in patients with moderate ischemic mitral regurgitation. J Thorac Cardiovasc Surg. 2014;147:1471-7.

5. Dahlberg PS, Orszulak TA, Mullany CJ, Daly RC, Enriquez-Sarano M, Schaff HV. Late outcome of mitral valve surgery for patients with coronary artery disease. Ann Thorac Surg. 2003;76:1539-48; discussion 1547-8.

6. Penicka M, Linkova H, Lang O, Fojt R, Kocka V, Vanderheyden M, et al. Predictors of improvement of unrepaired moderate ischemic mitral regurgitation in patients undergoing elective isolated coronary artery bypass graft surgery. Circulation. 2009;120:1474-81.

7. Michler RE, Smith PK, Parides MK, Ailawadi G, Thourani V, Moskowitz AJ, et al; CTSN. Two-year outcomes of surgical treatment of moderate ischemic mitral regurgitation. N Engl J Med. 2016;374:1932-41.

8. Campwala SZ, Bansal RC, Wang N, Razzouk A, Pai RG. Factors affecting regression of mitral regurgitation following isolated coronary artery bypass surgery. Eur J Cardiothorac Surg. 2005;28:783-7.

9. Fattouch K, Sampognaro R, Speziale G, Salardino M, Novo G, Caruso M, et al. Impact of moderate ischemic mitral regurgitation after isolated coronary artery bypass grafting. Ann Thorac Surg. 2010;90:1187-94.

10. Sun X, Huang J, Shi M, Huang G, Pang L, Wang Y. Predictors of moderate ischemic mitral regurgitation improvement after off-pump coronary artery bypass. J Thorac Cardiovasc Surg. 2015;149:1606-12.

11. Foster GP, Dunn AK, Abraham S, Ahmadi N, Sarraf G. Accurate measurement of mitral annular dimensions by echocardiography: importance of correctly aligned imaging planes and anatomic landmarks. J Am Soc Echocardiogr. 2009;22: 458-63.

12. Jassar AS, Brinster CJ, Vergnat M, Robb JD, Eperjesi TJ, Pouch AM, et al. Quantitative mitral valve modeling using real-time three-dimensional echocardiography: technique and repeatability. Ann Thorac Surg. 2011;91: 165-71.

13. Bonow RO, Carabello BA, Chatterjee K, de Leon AC Jr, Faxon DP, Freed MD, et al. American College of Cardiology/American Heart Association task force on practice guidelines. 2008 focused update incorporated into the ACC/AHA 2006 guidelines for the management of patients with valvular heart disease: a report of the American College of Cardiology/American Heart Association task force on practice guidelines (writing committee to revise the 1998 guidelines for the management of patients with valvular heart disease). Endorsed by the Society of Cardiovascular Anesthesiologists, Society for Cardiovascular Angiography and Interventions, and Society of Thoracic Surgeons. J Am Coll Cardiol. 2008; 52:e1-142.

14. Schiller NB, Shah PM, Crawford M, DeMaria A, Devereux R, Feigenbaum H, et al. Recommendations for quantitation of the left ventricle by two-dimensional echocardiography. American Society of Echocardiography committee on standards, subcommittee on quantitation of two-dimensional echocardiograms. J Am Soc Echocardiogr. 1989;2:358-67.

15. Bouma W, Lai EK, Levack MM, Shang EK, Pouch AM, Eperjesi TJ, et al. Preoperative three-dimensional valve analysis predicts recurrent ischemic mitral regurgitation after mitral annuloplasty. Ann Thorac Surg. 2016;101:567-75; discussion 575.

16. Smith PK, Puskas JD, Ascheim DD, Voisine P, Gelijns AC, Moskowitz AJ, et al; Cardiothoracic Surgical Trials Network Investigators. Surgical treatment of moderate ischemic mitral regurgitation. N Engl J Med. 2014;371:2178-88.

17. Benedetto U, Caputo M, Vohra H, Davies A, Hillier J, Bryan A, et al. Off-pump versus on-pump coronary artery bypass surgery in patients with actively treated diabetes and multivessel coronary disease. J Thorac Cardiovasc Surg. 2016;152: 1321-30.e12.

18. Salgo IS, Gorman JH III, Gorman RC, Jackson BM, Bowen FW, Plappert T, et al. Effect of annular shape on leaflet curvature in reducing mitral leaflet stress. Circulation. 2002;106:711-7. 
19. Jassar AS, Vergnat M, Jackson BM, McGarvey JR, Cheung AT, Ferrari G, et al. Regional annular geometry in patients with mitral regurgitation: implications for annuloplasty ring selection. Ann Thorac Surg. 2014;97:64-70.

20. Kron IL, Hung J, Overbey JR, Bouchard D, Gelijns AC, Moskowitz AJ, et al; CTSN Investigators. Predicting recurrent mitral regurgitation after mitral valve repair for severe ischemic mitral regurgitation. J Thorac Cardiovasc Surg. 2015;149:752-61.e1.

21. Wijdh-den Hamer IJ, Bouma W, Lai EK, Levack MM, Shang EK, Pouch AM, et al. The value of preoperative 3-dimensional over 2-dimensional valve analysis in predicting recurrent ischemic mitral regurgitation after mitral annuloplasty J Thorac Cardiovasc Surg. 2016;152:847-59.

22. Jeong DS, Lee HY, Kim WS, Sung K, Park PW, Lee YT. Off pump coronary artery bypass versus mitral annuloplasty in moderate ischemic mitra regurgitation. Ann Thorac Cardiovasc Surg. 2012;18:322-30.

Key Words: coronary artery bypass grafting, ischemic mitral regurgitation, annular geometry, leaflet tethering

Readers who found these articles interesting may also like to read the following papers found in recent and future issues of our sister publications, Seminars in Thoracic and Cardiovascular Surgery and Operative Techniques in Thoracic and Cardiovascular Surgery!

\section{Adult: Mitral Valve}

ORIGINAL SUBMISSION: Is Surgical or Catheter-based Interventions an Option After an Unsuccessful Mitral Clip? Felix Kreidel. Semin Thoracic Surg 2018: 152-157.

Editorial Commentary: With Every New Technology Comes a Learning Curve. Saina Attaran. Semin Thoracic Surg 2018: 158-159.

ORIGINAL SUBMISSION: Tiara Valve Implantation in a Patient With Previously Implanted Mono-disk Mechanical Aortic Prosthesis. Enrico Ferrari. Semin Thoracic Surg 2018: 160-163.

Editorial Commentary: Connubial Bliss or Distress? Transcatheter Mitral Valve Implantation With Mechanical Aortic Prostheses. Mohamad Alkhouli. Semin Thoracic Surg 2018: 164-165.

CASE REPORT: Minimally Invasive SAPIEN in Mitral Annular Calcification Following Transcatheter Aortic Valve Replacement: Feasibility and Lessons Learned. Tom C. Nguyen. Semin Thoracic Surg 2018: In press. 


\section{APPENDIX E1 \\ Repeatability Study (Shown in Table E1)}

To check the repeatability of the work, an intraobserver comparison study was performed. Ten cases were selected (first 5 cases included in the improved group and first 5 cases in the failure group), and the measurements of the nonplanar angle and mitral segmental tethering angles were performed again as acquisition 2. The Student paired $t$ test was used to evaluate for statistically significant difference between measurements at different acquisitions. Pearson correlation analysis was performed to assess correlation between measurements within each group, presented as the Pearson correlation coefficient $(R)$. The results demonstrated a high degree of repeatability in the measurements of annular and valve tethering variables, with no significant difference between acquisitions and with a high correlation coefficient.

\section{Sensitivity Analysis}

To evaluate and control the waiting time bias, sensitivity analysis was performed. The latest echocardiographic data of the 8 deaths before 1 year after surgery were included in the failure group ( 5 cases at 3 months after surgery and 3 cases at 6 months after surgery), and the univariate and multivariate regression analysis were performed again. As shown in Table E2, only nonplanar angle and P3 tethering angles emerged as independent predictors for IMR improvement at 1 postoperative year. 




FIGURE E1. Between May 2008 and Jan 2016, a total of 1231 patients underwent isolated coronary artery bypass grafting (CABG), and 109 patients underwent coronary artery bypass grafting combined with valvular surgeries. In the isolated coronary artery bypass grafting cases, 142 patients underwent on-pump coronary artery bypass grafting because of difficulty performing off-pump coronary artery bypass grafting $(O P C A B)$, and 1089 patients underwent OPCAB. Among these, 143 patients with moderate ischemic mitral regurgitation $(I M R)$ meeting inclusion criteria were involved in this study. Eight patients who died before 1-year follow-up were excluded; of the remainder, 65 patients were grouped into the improved group and 70 into the failure group.

TABLE E1. Intraobserver comparison

\begin{tabular}{lrrrc}
\hline \multicolumn{1}{c}{ Variable } & Acquisition 1 & Acquisition 2 & $\begin{array}{c}\boldsymbol{P} \\
\text { value }\end{array}$ & $\begin{array}{c}\mathbf{C C} \\
(\boldsymbol{R})\end{array}$ \\
\hline Nonplanar angle $\left(^{\circ}\right)$ & $156.7^{\circ} \pm 9.1^{\circ}$ & $157.5^{\circ} \pm 9.8^{\circ}$ & .852 & 0.906 \\
A1 tethering angle $\left(^{\circ}\right)$ & $30.4^{\circ} \pm 8.8^{\circ}$ & $29.6^{\circ} \pm 8.7^{\circ}$ & .847 & 0.900 \\
\hline A2 tethering angle $\left(^{\circ}\right)$ & $27.9^{\circ} \pm 7.0^{\circ}$ & $28.6^{\circ} \pm 6.7^{\circ}$ & .823 & 0.934 \\
A3 tethering angle $\left(^{\circ}\right)$ & $24.4^{\circ} \pm 5.5^{\circ}$ & $25.3^{\circ} \pm 4.7^{\circ}$ & .690 & 0.948 \\
P1 tethering angle $\left(^{\circ}\right)$ & $28.3^{\circ} \pm 5.8^{\circ}$ & $28.9^{\circ} \pm 4.2^{\circ}$ & .794 & 0.834 \\
P2 tethering angle $\left(^{\circ}\right)$ & $36.6^{\circ} \pm 8.6^{\circ}$ & $37.5^{\circ} \pm 6.3^{\circ}$ & .793 & 0.928 \\
\hline P3 tethering angle $\left(^{\circ}\right)$ & $29.6^{\circ} \pm 7.5^{\circ}$ & $30.3^{\circ} \pm 5.5^{\circ}$ & .838 & 0.923 \\
\hline
\end{tabular}

$C C$, Correlation coefficient.
TABLE E2. Predictors of ischemic mitral regurgitation improvement by binary logistic regression (sensitivity analysis)

\begin{tabular}{lccc}
\hline \multicolumn{1}{c}{ Determinants } & Coefficient \pm SE & OR $(\mathbf{9 5} \% \mathbf{C I})$ & $\begin{array}{c}\boldsymbol{P} \\
\text { value }\end{array}$ \\
\hline Nonplanar angle & $-0.266 \pm 0.063$ & $0.766(0.677-0.867)$ & $<0.001$ \\
P3 tethering angle & $-0.365 \pm 0.075$ & $0.694(0.599-0.804)$ & $<0.001$ \\
\hline A3 tethering angle & $-0.049 \pm 0.037$ & $0.952(0.885-1.025)$ & 0.190 \\
P1 tethering angle & $-0.012 \pm 0.040$ & $0.988(0.914-1.068)$ & 0.764 \\
\hline P2 tethering angle & $-0.022 \pm 0.035$ & $0.979(0.914-1.048)$ & 0.535 \\
Ejection fraction & $0.016 \pm 0.025$ & $1.016(0.968-1.066)$ & 0.525 \\
\hline
\end{tabular}

$O R$, Odds ratio; $C I$, confidence interval. 